\title{
Verification and Validation of a Methodology to Numerically Generate Waves Using Transient Discrete Data as Prescribed Velocity Boundary Condition
}

\author{
Rafael P. Maciel ${ }^{1}\left(\mathbb{D}\right.$, Cristiano Fragassa ${ }^{2, *}$, , Bianca N. Machado ${ }^{3}{ }^{\circledR}$, Luiz A. O. Rocha $^{4}(\mathbb{D}$, \\ Elizaldo D. dos Santos ${ }^{1} \mathbb{D}$, Mateus N. Gomes ${ }^{5}$ and Liércio A. Isoldi ${ }^{1}{ }^{\mathbb{D}}$ \\ 1 School of Engineering, Federal University of Rio Grande (FURG), Italia Av., km 8, \\ Rio Grande 96203-900, RS, Brazil; rafaelmacie195@hotmail.com (R.P.M.); elizaldosantos@furg.br (E.D.d.S.); \\ liercioisoldi@furg.br (L.A.I.) \\ 2 Department of Industrial Engineering, University of Bologna, Viale Risorgimento 2, 40136 Bologna, Italy \\ 3 Interdisciplinary Department, Federal University of Rio Grande do Sul (UFRGS), RS 030, \\ 11.700-Km 92 Emboaba, Tramandaí 95590-000, RS, Brazil; bianca.machado@ufrgs.br \\ 4 Polytechnic School, University of the River Bells Valley (UNISINOS), Unisinos Av., 950, \\ São Leopoldo 93022-750, RS, Brazil; luizor@unisinos.br \\ 5 Federal Institute of Paraná (IFPR), Antônio Carlos Rodrigues Av., 453, Paranaguá 83215-750, PR, Brazil; \\ mateus.gomes@ifpr.edu.br \\ check for \\ updates \\ * Correspondence: cristiano.fragassa@unibo.it; Tel.: +39-347-697-4046
}

Citation: Maciel, R.P.; Fragassa, C.; Machado, B.N.; Rocha, L.A.O.; dos Santos, E.D.; Gomes, M.N.; Isoldi, L.A. Verification and Validation of a Methodology to Numerically Generate Waves Using Transient Discrete Data as Prescribed Velocity Boundary Condition. J. Mar. Sci. Eng. 2021, 9, 896. https://doi.org/ 10.3390/jmse9080896

\section{Academic Editors:}

Charitha Pattiaratchi and Christos Stefanakos

Received: 26 June 2021

Accepted: 16 August 2021

Published: 19 August 2021

Publisher's Note: MDPI stays neutral with regard to jurisdictional claims in published maps and institutional affiliations.

Copyright: (c) 2021 by the authors. Licensee MDPI, Basel, Switzerland. This article is an open access article distributed under the terms and conditions of the Creative Commons Attribution (CC BY) license (https:// creativecommons.org/licenses/by/ $4.0 /)$.

\begin{abstract}
This work presents a two-dimensional numerical analysis of a wave channel and a oscillating water column (OWC) device. The main goal is to validate a methodology which uses transient velocity data as a means to impose velocity boundary condition for the generation of numerical waves. To achieve this, a numerical wave channel was simulated using regular waves with the same parameters as those used in a laboratory experiment. First, these waves were imposed as prescribed velocity boundary condition and compared with the analytical solution; then, the OWC device was inserted into the computational domain, aiming to validate this methodology. For the numerical analysis, computational fluid dynamics ANSYS Fluent software was employed, and to tackle with water-air interaction, the nonlinear multiphase model volume of fluid (VOF) was applied. Although the results obtained through the use of discrete data as velocity boundary condition presented a little disparity; in general, they showed a good agreement with laboratory experiment results. Since many studies use regular waves, there is a lack of analysis with ocean waves realistic data; thus, the proposed methodology stands out for its capacity of using realistic sea state data in numerical simulations regarding wave energy converters (WECs).
\end{abstract}

Keywords: wave energy; oscillating water column; transient discrete data; boundary condition; numerical simulation

\section{Introduction}

Nowadays, it is estimated that the global energy consumption is already six times greater than it was in 1950 and it is projected to grow at around $55 \%$ by 2030 [1]. Considering the environmental impact of using traditional energy sources, there is a growing search for alternative energy sources. In this scenario, renewable energies stand out, since they come from regenerative resources, do not deplete over time, and have low environmental impact, in addition to reducing carbon emissions [2]. Although approximately $80 \%$ of the global primary energy comes from fossil fuels, Brazil stands out in terms of the use of renewable sources, where these represent $80.4 \%$ of the domestic electricity supply [3,4]. Among the various renewable energy sources, oceans are gaining prominence, since they cover more than $70 \%$ of the Earth's surface [5]. Although progress in the commercialization of ocean energy is still relatively slow, the energy potential of the oceans is promising; part 
of this is due to the fact that the technology needed to harvest and produce this type of energy is still under development [6]. Recently, Espindola and Araújo [7] mapped the capacity, in $\mathrm{kW} / \mathrm{m}$, along the Brazilian coast, concluding that the mean wave power varies around 8 to $21 \mathrm{~kW} / \mathrm{m}$. Among the different types of devices which convert sea wave energy into electrical energy, the oscillating water column (OWC) type device is possibly the most extensively studied [8]. An OWC device consists basically of four parts, these are hydropneumatic chamber, turbine duct, turbine and generator. The hydropneumatic chamber, which can be fixed or floating, is a structure whose bottom is open, below the water surface, thus retaining the air trapped inside the chamber and above the free surface; the movement of the waves then causes the air to be continuously compressed and decompressed, flowing through a turbine coupled to a generator. A schematic representation of this device operating principle can be seen in Figure 1.

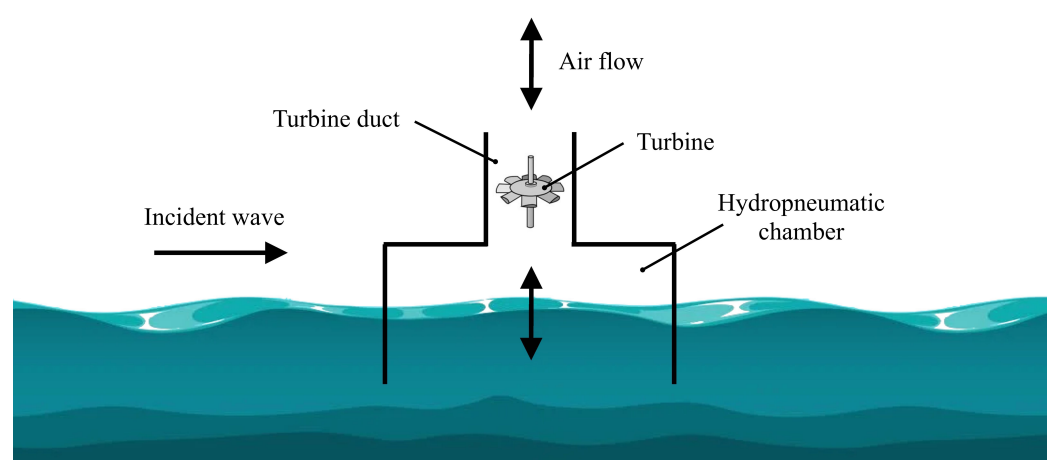

Figure 1. Schematic representation of the operating principle of an OWC device.

Studies concerning the OWC device have been carried out, addressing numerical and experimental evaluations of the geometric characteristics of the device, conversion capacity, energy conversion mechanism, hydrodynamic performance, location of the device and energy availability. However, since each installation site possesses unique wave characteristics, carrying out numerous prototype tests becomes financially demanding [9]. Therefore, numerical simulations have been increasingly employed in analyses of wave energy converters (WECs). To achieve this, many techniques have been developed to simulate the generation of numerical waves in coastal scenarios. In this context, a few stand out for their use with wave channels. The first techniques were originated from wavemaker theories, which describe wave generation through the displacement of water using rigid bodies. These theories play an important role regarding application to laboratory wavemakers for wave experiments [10]. It should be noted that there are several types of wavemakers, classified according to the movement that causes water displacement, and the most common are flap (or hinged), piston, and plunger [11]. The aforementioned techniques consist of numerically reproducing the operational principle of wavemakers. In the piston-type wavemaker, a movable wall oscillates horizontally, generating waves. Previous studies have applied this type of wavemaker to evaluate the generation of numerical waves and analyze WECs, such as OWC and overtopping devices [12-15]. More commonly used for testing ships and structures in deep water, the flap-type wavemaker is a moving partition which rotates around a horizontal axis [16]. It has been employed to study alternative shapes for numerical wave channels, generation of irregular waves, and wave breaking limit [17-19]. Although less common, the plunger-type wavemaker has also been used in the study of numerical waves. It consists of a plunger, which moves up and down, causing water displacement and generating waves. It has been applied to study the generation of regular and solitary waves, and the inclusion of current in a water channel [20-23]. It should be mentioned that these wavemakers are numerically implemented through user-defined functions (UDFs) and use dynamic mesh to perform wave generation, which, in turn, require more computational effort [24]. Therefore, to generate numerical waves with lower computational cost, UDFs have been employed with a simpler approach. In this 
procedure, horizontal and vertical components of wave velocity, obtained from the velocity potential, are applied as boundary conditions [25-32]. To achieve results in agreement with real ocean waves and sea states, irregular waves have also been thoroughly studied. A common method for the generation of irregular waves and realistic sea states is the use of wave spectra [33-39]. In summary, to study the various aspects present in a WEC such as an OWC device, wave generation is of paramount importance.

In this context, Liu et al. [14] reproduced a numerical wave tank, using a piston-type wavemaker, to analyze the effects of incident wave conditions and shape parameters of an OWC device over the wave energy conversion efficiency. Machado et al. [9] computationally analyzed a numerical wave channel in laboratory scale and real scale, applying a new system to impose velocity boundary condition for numerical waves generation, using transient discrete values. For this, they compared the magnitude of the numerical waves generated by this procedure with the numerical waves generated through the imposition of prescribed velocities. Though the authors found that the proposed computational model, using discrete data as velocity boundary conditions for numerical waves generation, could be satisfactorily applied, it was not validated against experimental results. Lisboa et al. [30] numerically analyzed the available power of an OWC device fixed on a breakwater, with a Wells turbine, installed on the south coast of Brazil. An analysis of the wave occurrence in the region was carried out in order to determine the significant parameters used in the numerical analysis. Considering the wave characteristics of the region, the authors found an optimum diameter of $2.25 \mathrm{~m}$ for the turbine and an average annual power of $36.48 \mathrm{~kW}$ for the OWC device. Zabihi et al. [40] employed a fully nonlinear two phase flow model using Ansys Fluent to investigate the hydrodynamics of an OWC, which was validated against a relatively large scale physical model (1:15). For that, they compared results of both free surface elevation and air pressure in the OWC chamber. The authors reached an admissible accordance between numerical and experimental models, although some discrepancies were detected in the free surface elevation inside the hydropneumatic chamber, especially for short wave periods. On the other hand, when assessing the characteristics of installation sites, the random character of ocean waves makes the use of realistic sea states in numerical studies a challenge. Thus, the use of representative regular waves for the purpose of representing sea states has been widely used. However, the analysis made with regular waves can lead to results, such as available power, pressure, and velocity, which do not correspond to reality [39]. In this context, the methodology proposed by Machado et al. [9] stands out for its capacity of allowing the use of realistic sea state data in numerical simulations regarding WECs. Thus, the main goal of this paper is to validate this methodology, which uses transient velocity data as a means to impose velocity boundary condition for the generation of numerical waves. Hence, the current work presents a two-dimensional numerical analysis of a wave channel and a laboratory scale OWC device, both used in laboratory experiments [40]. For the proposed analysis, a numerical wave channel was simulated using regular waves with the same wave parameters as those used in the experiments. First, considering only the wave channel, the regular waves were imposed as prescribed velocity boundary conditions, and a verification of the methodology was carried out comparing its results with those obtained by the analytical solution. Then, the OWC was inserted in the wave channel and the numerical results were compared with the experimental results presented by Zabihi et al. [40].

\section{Materials and Methods}

\subsection{Mathematical and Numerical Model}

To perform the numerical simulations in this study, ANSYS Fluent software was used, which is a computational fluid dynamics (CFD) commercial code based on the finite volume method (FVM). This software provides comprehensive modeling capabilities for a wide range of incompressible and compressible, laminar and turbulent fluid flow problems [41].

In this study, to tackle with water-air interaction, a nonlinear multiphase model was employed. The motion of fluid flow throughout the mixture is described by the continu- 
ity equation and the momentum conservation equations, which, for a two-dimensional domain, are as follows [42,43]:

$$
\begin{gathered}
\frac{\partial u}{\partial x}+\frac{\partial w}{\partial z}=0 \\
\rho \frac{\partial u}{\partial t}+\rho\left(u \frac{\partial u}{\partial x}+w \frac{\partial u}{\partial z}\right)=-\frac{\partial p}{\partial x}+\mu\left(\frac{\partial^{2} u}{\partial x^{2}}+\frac{\partial^{2} u}{\partial z^{2}}\right)+S \\
\rho \frac{\partial w}{\partial t}+\rho\left(u \frac{\partial w}{\partial x}+w \frac{\partial w}{\partial z}\right)=-\frac{\partial p}{\partial z}+\mu\left(\frac{\partial^{2} w}{\partial x^{2}}+\frac{\partial^{2} w}{\partial z^{2}}\right)+\rho g+S
\end{gathered}
$$

where $u$ and $w$ are the velocity components in $x$ and $z$ directions (m/s), respectively, $\rho$ is density $\left(\mathrm{kg} / \mathrm{m}^{3}\right), t$ is time $(\mathrm{s}), p$ is static pressure $\left(\mathrm{N} / \mathrm{m}^{2}\right), \mu$ is the absolute viscosity coefficient $(\mathrm{kg} / \mathrm{m} \cdot \mathrm{s}), S$ is a damping sink term used in the numerical beach, and $\rho g$ is the gravitational body force $\left(\mathrm{N} / \mathrm{m}^{3}\right)$.

It is worth mentioning that Reynolds averaged Navier-Stokes (RANS) equations were used, which are based on the decomposition of the instantaneous velocity and pressure fields of the Navier-Stokes equations into mean and fluctuating components, and the subsequent time-averaging of the set of equations. This process introduces Reynolds stress terms associated with turbulence [44]. Thus, in addition to analyzing the domain in a laminar flow regime, two turbulence models which could close the set of equations were compared: $k-\epsilon$ and shear stress transport (SST) $k-\omega$ turbulence models.

The nonlinear multiphase model adopted uses the surface-tracking volume of fluid (VOF) technique [45], which can model two or more immiscible fluids and track the volume fraction $(\alpha)$ of these fluids inside each element throughout the domain. Thus, according to volume fraction values for a domain composed of water and air, three situations are possible: if $\alpha$ is equal to 0 , that means the cell is empty of water and filled exclusively by air; if $\alpha$ is equal to 1 , that means the cell is full of water; and if $\alpha$ is equal to any other value between 0 and 1 , that means the cell contains the interface between the two phases. The volume fraction for the two phases throughout the two-dimensional domain follows a transport equation as shown $[46,47]$ :

$$
\frac{\partial \alpha}{\partial t}+\frac{\partial \alpha u}{\partial x}+\frac{\partial \alpha w}{\partial z}=0
$$

The values for density and absolute viscosity coefficient, fluid properties present in the momentum conservation equations (Equations (2) and (3)) are then determined as follows [47]:

$$
\begin{aligned}
& \rho=\alpha \rho_{\text {water }}+(1-\alpha) \rho_{\text {air }} \\
& \mu=\alpha \mu_{\text {water }}+(1-\alpha) \mu_{\text {air }}
\end{aligned}
$$

As wave reflection may interfere with surface elevation along the channel, a numerical beach was inserted at the end of the domain. In this case, a damping sink term $(S)$ is added to the momentum equation for the cell zone in the vicinity of the pressure outlet boundary [41]:

$$
S=-\left[C_{1} \rho V+\frac{1}{2} C_{2} \rho|V| V\right]\left(1-\frac{z-z_{f_{s}}}{z_{b}-z_{f_{s}}}\right)\left(\frac{x-x_{s}}{x_{e}-x_{s}}\right)^{2}
$$

where $C_{1}$ and $C_{2}$ are linear and quadratic damping coefficients, respectively, $V$ is the velocity along vertical direction $(\mathrm{m} / \mathrm{s}), z$ is the distance from free surface level $(\mathrm{m}), z_{f s}$ and $z_{b}$ are the free surface and bottom coordinates along vertical direction $(\mathrm{m})$, respectively, $x$ is the horizontal coordinate $(\mathrm{m})$, and $x_{s}$ and $x_{e}$ are the start and end points of the numerical beach in the horizontal direction $(\mathrm{m})$, respectively.

As previously mentioned, the methodology used in this study consists of generating numerical waves through the imposition of discrete transient data of orbital wave velocity in vertical and horizontal directions. To obtain the values used in the imposition of 
prescribed velocity boundary conditions, and to perform an analytical comparison with the results, the 2 nd order Stokes wave equation was employed. Therefore, the horizontal and vertical wave velocity components and the water surface displacement $(\eta)$ are [11]:

$$
\begin{gathered}
u=\frac{H}{2} \frac{g k}{\omega} \frac{\cosh k(h+z)}{\cosh (k h)} \cos (k x-\omega t)+\frac{3 H^{2} \omega k}{16} \frac{\cosh [2 k(h+z)]}{\sin ^{4}(k h)} \cos 2(k x-\omega t), \\
w=\frac{H}{2} \frac{g k}{\omega} \frac{\sinh k(h+z)}{\cosh (k h)} \sin (k x-\omega t)+\frac{3 H^{2} \omega k}{16} \frac{\sinh [2 k(h+z)]}{\sin ^{4}(k h)} \sin 2(k x-\omega t), \\
\eta=\frac{H}{2} \cos (k x-\omega t)+\frac{H^{2} k}{16} \frac{\cosh (k h)}{\sinh ^{3}(k h)}[2+\cosh (2 k h)] \cos 2(k x-\omega t),
\end{gathered}
$$

where $H$ represents the wave height $(\mathrm{m}), k$ is the wave number $\left(\mathrm{m}^{-1}\right), h$ is the channel water depth $(\mathrm{m})$, and $\omega$ is the wave angular frequency ( $\mathrm{rad} / \mathrm{s})$.

Lastly, to assist in comparing the results, the Normalized Root Mean Squared Error (NRMSE) for each simulation was measured. The NRMSE is calculated using the following equation $[48,49]$ :

$$
\text { NRMSE }=\frac{\sqrt{\frac{1}{n} \sum_{i=1}^{n}\left(S_{i}-O_{i}\right)^{2}}}{O_{\max }-O_{\min }},
$$

where $S_{i}$ represents the values obtained from simulations, $O_{i}$ represents the observation, i.e., the analytical solution or experimental results, $n$ is the number of observations available for analysis, and $O_{\max }$ and $O_{\min }$ indicate the maximum and minimum observation values, respectively.

\subsection{Numerical Simulations}

When dealing with numerical simulations of coastal scenarios, proper wave generation is a fundamental step to achieve reliable results. The computational domain in this case is a two-dimensional numerical wave channel (NWC), with a length of $65 \mathrm{~m}$, which corresponds to approximately 9 times the wavelength $(L=7.54 \mathrm{~m})$, height of $6 \mathrm{~m}$, and water depth $(h)$ of $4 \mathrm{~m}$. As adopted by Lisboa et al. [34], two wavelengths on the extremity of the NWC have been dedicated to be a numerical beach, thus being responsible for wave damping and avoiding wave reflection.

As mentioned, a NWC was simulated using the Fluent software applying the proposed methodology and two simulations were performed. The first simulation aimed to perform a verification of the wave generation and propagation, simulating 2 nd order Stokes waves and then comparing the results with its analytical solution (Equation (10)). For that, the following boundary conditions have been assigned to the computational domain, as shown in Figure 2: on the left, in green and purple, the prescribed velocity boundary condition was assigned; at the bottom, in blue, the no-slip wall boundary condition was imposed; on the left and at the top, in red, the pressure outlet boundary condition was used with an atmospheric pressure value of 101,325 Pa; lastly, on the right, a special pressure outlet boundary condition was assigned, using a hydrostatic pressure profile, as adopted by Lisboa et al. [34]. Additionally, the surface water line (SWL) is represented by the dashed line.

In the second simulation, the methodology was validated; an OWC device was inserted to reproduce a laboratory experiment performed by Zabihi et al. [40]. The wave parameters adopted were the same for both simulations, where the height of the simulated wave was $0.15 \mathrm{~m}$ and its period was $2.2 \mathrm{~s}$, following the values used in the experiment.

The proposed methodology was used to impose the prescribed velocity boundary condition. It presents a geometric particularity, which is, for discrete transient data imposition as boundary conditions of velocity inlet, it is necessary that this region of geometry is divided into subregions (green and purple lines), as shown in Figure 3 [9]. 


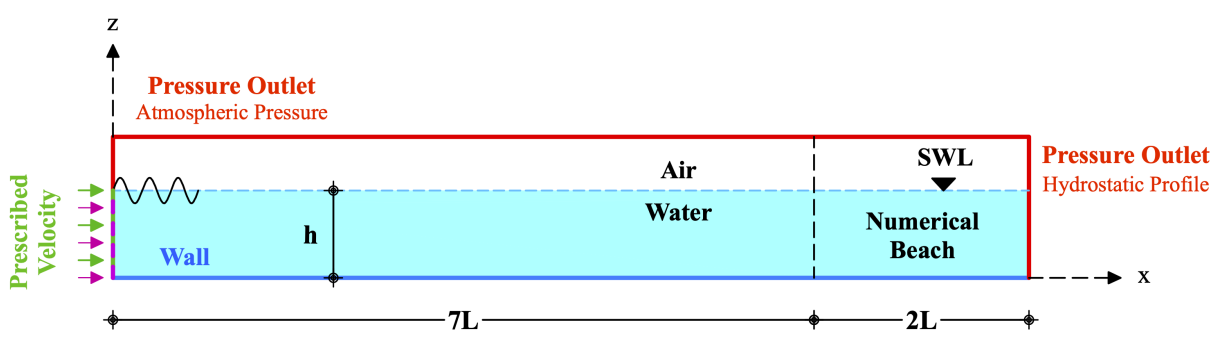

Figure 2. Computational domain used in this study for the methodology verification.

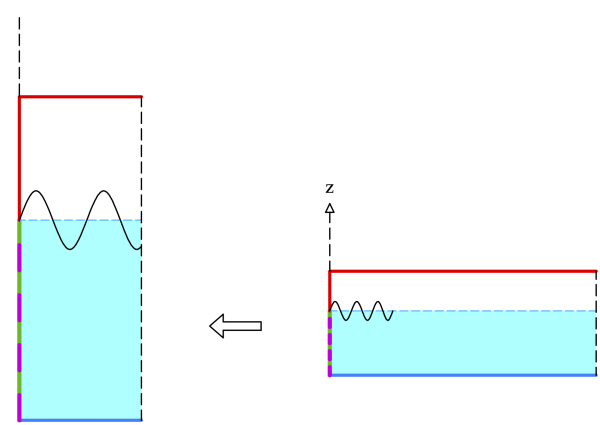

Figure 3. Sketch of boundary condition fractioning region used in the wave generation with the proposed methodology.

As shown in Figures 2 and 3, the prescribed velocity boundary condition is assigned to the line segments at the entrance of the channel. Each segment receives different values corresponding to the horizontal and vertical wave velocity components $u$ and $w$, respectively. However, the optimal discretization, i.e., the number of line segments that provides a proper wave generation, must be analyzed. Therefore, the number of segments were evaluated over 2 min of simulation, comparing free surface elevation when using 5, 8, 10 , and 16 line segments at the velocity inlet region.

Since the mean water level in the wave channel is $4 \mathrm{~m}$, the length of each segment changes according to the total amount of segments. For example, when using 5 line segments at the entrance, each segment has a length of $0.80 \mathrm{~m}$; when using 8 segments at the entrance, each one has a length of $0.50 \mathrm{~m}$, and so on. The domain geometry and mesh were generated using GMSH software [50].

As presented in Section 2.1, the numerical beach equation has a linear $\left(C_{1}\right)$ and a quadratic $\left(C_{2}\right)$ damping coefficient, which allows for the calibration of the numerical beach. Similar calibrations were previously carried out, where good results were achieved with $C_{2}=0[34,51]$. Therefore, simultaneously to the velocity inlet boundary condition testing, 5 values of $C_{1}$ were tested, as shown in Figure 4, over simulations of $2 \mathrm{~min}$ to analyze the efficiency of these parameters.

Once the numerical beach was calibrated, mesh discretization was studied. For that, four different mesh sets were analyzed. In each set, different horizontal and vertical sizes of mesh elements were tested, assuming the values shown in Table 1 , where $L$ is the wavelength and $H$ is the wave height. In addition, a refinement zone, with a height twice the height of the incoming wave, was applied to the area nearing the free surface, through the entire length of the channel. Outside the refinement zone, along the channel, elements had a square shape with equal length and height, as it can be seen in Figure 5.

To ensure a proper wave generation, temporal discretization was also studied and time step $(\Delta t)$ tests were performed. Liu et al. [14] indicate that numerical accuracy is ensured when $\Delta t$ is less than $T / 50$, where $T$ is the wave period. Therefore, $\Delta t$ values of $T / 50, T / 100, T / 200, T / 400$, and $T / 800$ were tested. It is worth highlighting that, before this test was performed, the time step adopted for the simulations was $\mathrm{T} / 400$ [40]. 


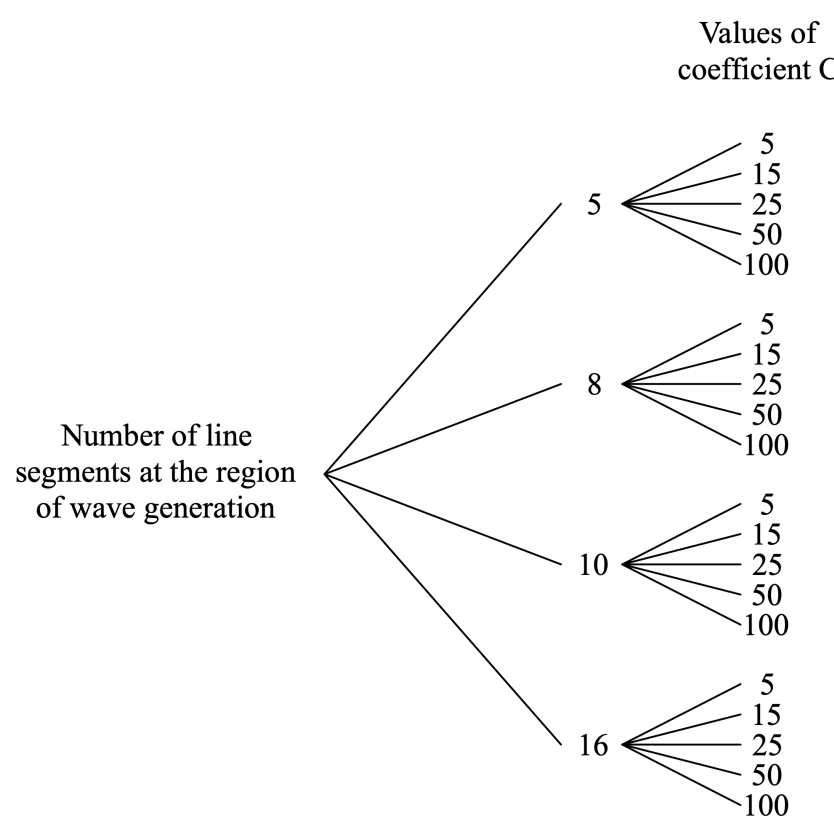

Figure 4. Number of line segments at the region of wave generation and values of coefficient $C_{1}$ used in the mesh independence study.

Table 1. Length and height of mesh elements used in the mesh independence study.

\begin{tabular}{ccc}
\hline & $\begin{array}{c}\text { Length and Height of Mesh } \\
\text { Elements throughout the } \\
\text { Channel }\end{array}$ & $\begin{array}{c}\text { Height of Mesh Elements } \\
\text { Inside Free Surface } \\
\text { Refinement Zone }\end{array}$ \\
\hline Mesh 1 & $L / 10$ & $H / 10$ \\
Mesh 2 & $L / 20$ & $H / 15$ \\
Mesh 3 & $L / 30$ & $H / 20$ \\
Mesh 4 & $L / 40$ & $H / 25$ \\
\hline
\end{tabular}

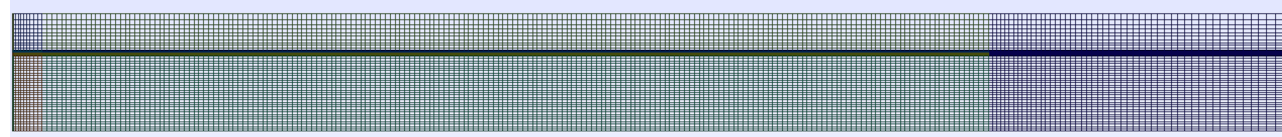

Figure 5. Two-dimensional mesh used in this study for wave generation verification.

With all parameters tested, regular 2nd order Stokes waves were simulated in the channel and its results were compared with the analytical solution, given by Equation (10). After all tests which ensure a proper wave generation, an OWC WEC device with the dimensions as those used by Zabihi et al. [40] was inserted in the channel.

In the mentioned experiment, a fixed OWC model of 1:15 scale was used, with a length of $0.80 \mathrm{~m}$, width of $0.92 \mathrm{~m}$, and $1.11 \mathrm{~m}$ of height (Figure 6). The experiments were performed in a wave tank $400 \mathrm{~m}$ long, $6 \mathrm{~m}$ wide, and $4 \mathrm{~m}$ high. Regular waves with a wave height of $0.15 \mathrm{~m}$ and three wave periods of $1.8,2.0$, and $2.2 \mathrm{~s}$ were used. It is worth mentioning the authors observed that short period waves entering the device could reflect from the chamber rear wall, interacting with incoming waves and resulting in higher nonlinearity; therefore, the $2.2 \mathrm{~s}$ wave period was adopted for the numerical simulations.

In addition, for the computational domain, a simplification regarding the experiments was made. In the laboratory, the distance between the OWC model and each side wall of the tank was $2.54 \mathrm{~m}$; since this value is more than twice the width of the OWC model, wave reflection was considered negligible. Therefore, a two-dimensional computational domain was adopted for this study. Figure 6 shows the dimensions of the physical model, as well as its cross-section, used in the two-dimensional computational domain, and Figure 7 shows the computational domain used in the validation procedure. 


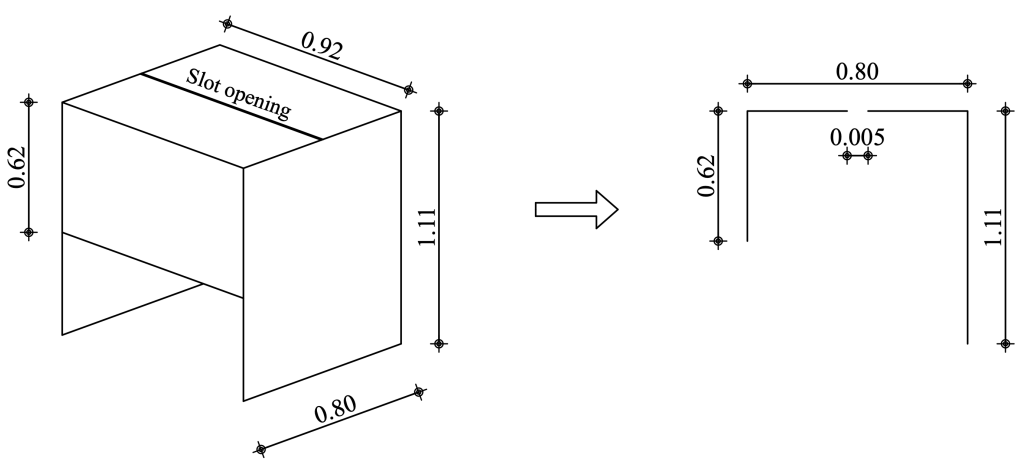

Figure 6. Dimensions of the physical model used in the experiments of Zabihi et al. [40] and of its cross-section (in m).

In addition to the spatial discretization tested for the wave channel, a refinement zone of two wavelengths, i.e., one wavelength to each side of the OWC, was applied to the area around the device. Inside this refinement zone, mesh elements had a horizontal and vertical size of $0.01 \mathrm{~m}$, except for the slot opening region, where the horizontal size of elements were $0.0025 \mathrm{~m}$. The mesh used for the study validation can be seen in Figure 8 .

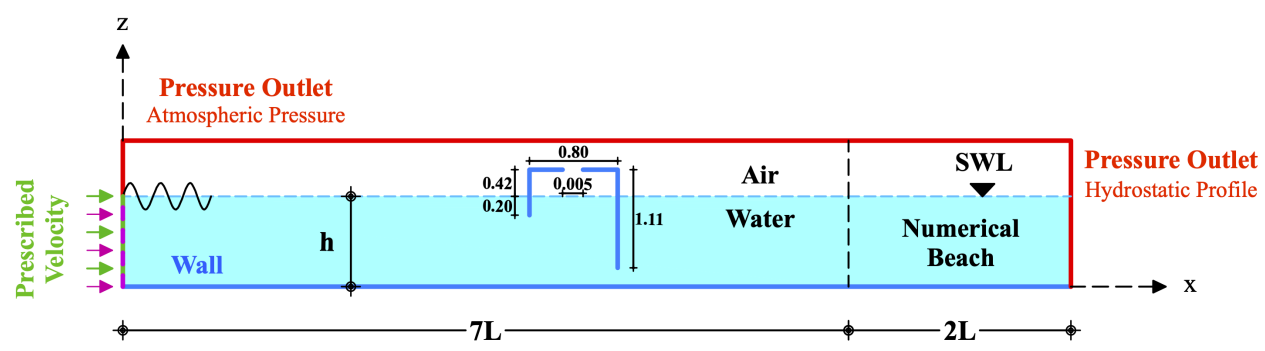

Figure 7. Computational domain used for validation of the proposed methodology.

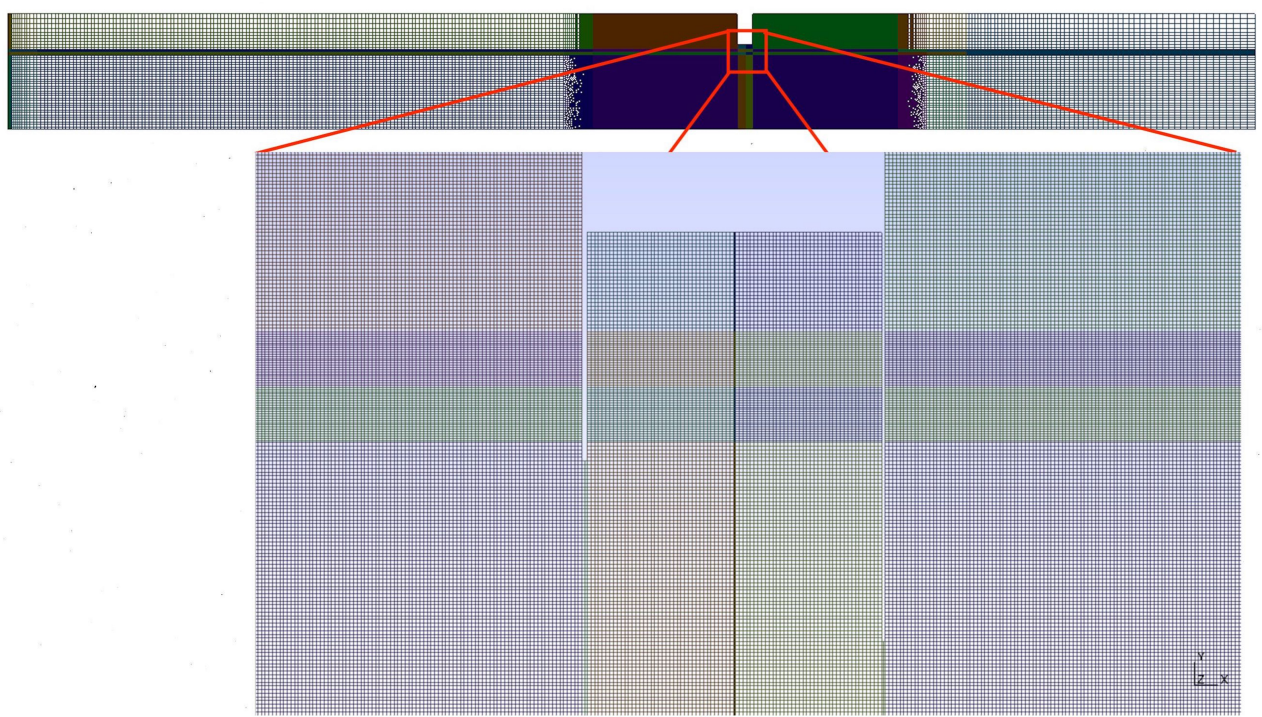

Figure 8. Discretization of the computational domain employed in the methodology validation.

To measure water free surface elevation and air pressure, 4 numerical wave gauges (WG) and a pressure sensor (PS) were used. From these, 2 wave gauges were positioned previously to the front wall of the device and all the others were positioned inside the hydropneumatic chamber of the computational domain. The front wall of the OWC device was positioned $38 \mathrm{~m}$ from the beginning of the wave tank. Figure 9 indicates the location of the sensor and gauges positioned in the chamber and along the wave tank. 

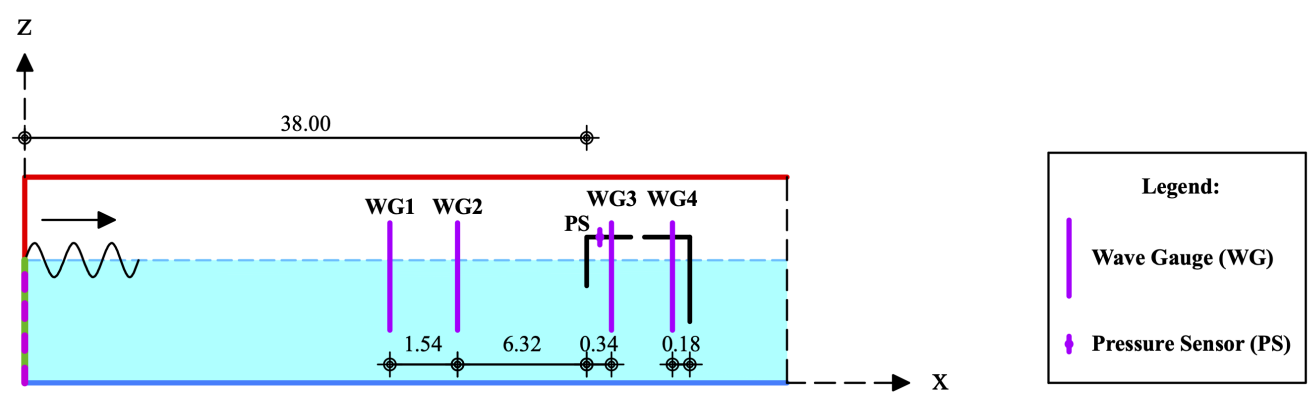

Figure 9. Location of wave gauges and pressure sensors.

In addition to spatial and temporal discretization, other numerical parameters were also defined and adopted for the verification and validation. A pressure-based solver was used for the numerical simulation. To solve the problem of linear dependence of velocity on pressure, the velocity-pressure coupling scheme pressure-implicit with splitting of operators (PISO) was adopted. A first order upwind scheme was applied for the discretization of spatial derivatives in the momentum equations, and a first order implicit formulation was adopted for time discretization. For the volume fraction, the geo-reconstruct method was applied; and for pressure interpolation at volume faces, the pressure staggering option (PRESTO!) scheme was used. In the verification simulations, only laminar flow was considered, and for the validation case two turbulence models were also considered: $k-\epsilon$ and $k-\omega$ shear stress transport (SST).

\section{Results}

This section presents the results obtained for the two cases analyzed in this study. To do so, it was divided into a few subsections: wave generation tests, numerical beach examination, mesh quality study, time step analysis, and study of the wave channel with the OWC device inserted, which led to the validation of the methodology proposed by Machado et al. [9].

\subsection{Verification}

\subsubsection{Wave Generation and Numerical Beach}

As previously mentioned, the proposed methodology relies on the imposition of discrete wave velocity components, used as boundary conditions. Therefore, the spatial discretization at the region of velocity imposition is of prime importance. As shown in Figure 4, four discretization arrangements were tested.

Figure 10 shows the free surface elevation at $x=10 \mathrm{~m}$ for each velocity imposition discretization, as well as the analytical solution for a regular second order Stokes wave. It is important to mention that the dimensionless parameter $t / T$ was used to present the ratio between simulated time $(t)$ and wave period $(T)$.

To assist choosing the optimal discretization of the wave generation region, NRMSE was calculated using Equation (11), with relation to the analytical solution. The NRMSE value for each simulation is presented in Table 2.

Table 2. NRMSE values for each velocity inlet discretization at the wave generation region.

\begin{tabular}{cc}
\hline Discretization & NRMSE (\%) \\
\hline 5 line segments & 3.99 \\
8 line segments & 2.79 \\
10 line segments & 6.20 \\
16 line segments & 4.21 \\
\hline
\end{tabular}




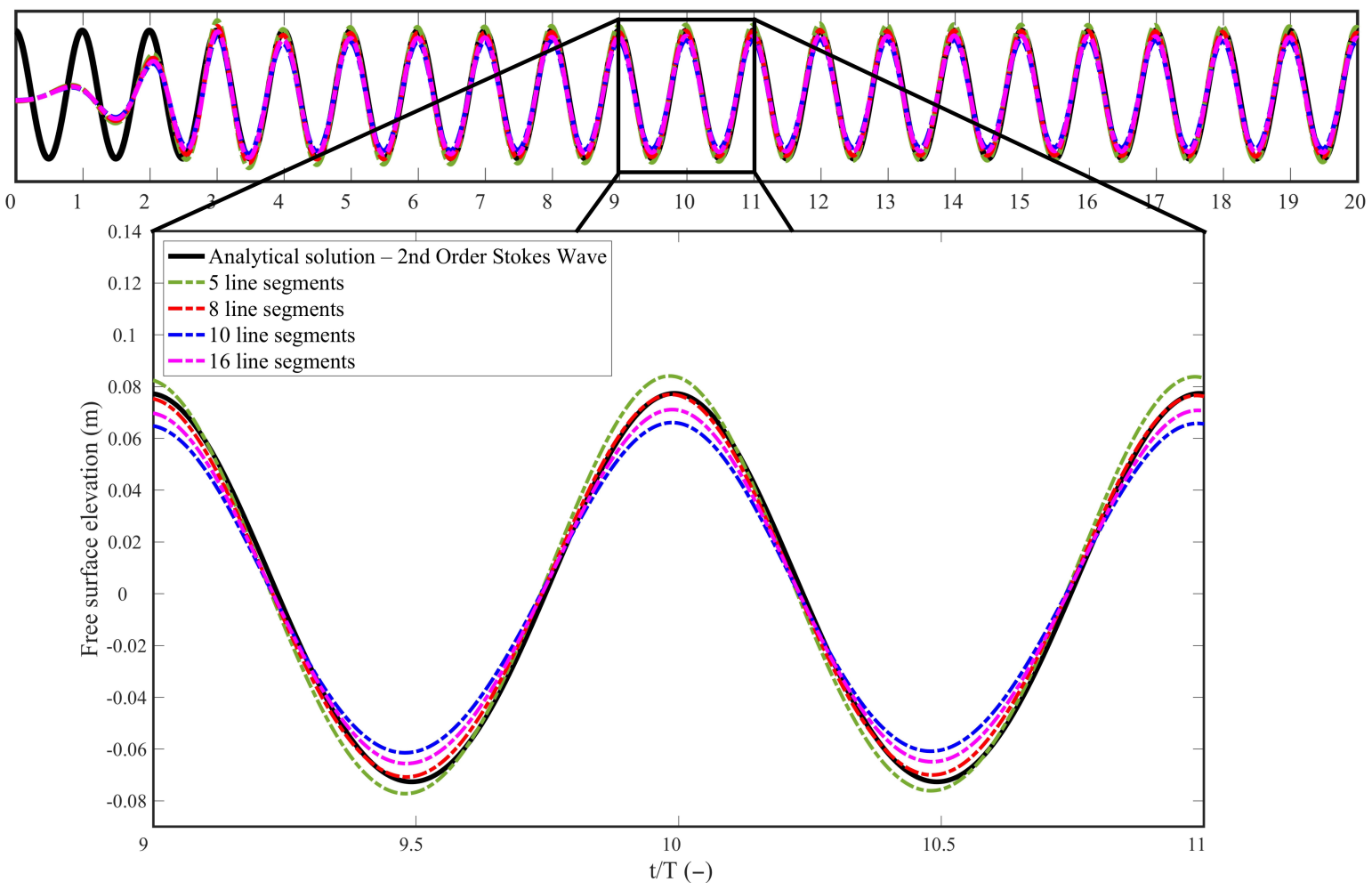

Figure 10. Comparison of the discretization at the wave generation region.

As shown in Table 2, the velocity inlet discretization which presented the smallest percentage of error was the one with eight velocity profiles, with a NRMSE value of $2.79 \%$. This result is in accordance with that achieved by Machado et al. [9]; therefore, this number was adopted for the upcoming simulations.

As mentioned in Section 2.2, a numerical beach was also implemented to prevent wave reflection at the end of the wave channel, which would interfere with free surface elevation along the channel. For a proper wave damping, five linear damping coefficient $\left(C_{1}\right)$ values were tested, as presented in Figure 4 . Figure 11 shows the free surface elevation at the end of the channel for each value of $C_{1}$ adopted.

To measure the wave damping efficiency, a ratio between the wave height obtained at the end of the channel $(x=65.00 \mathrm{~m})$ and the wave height at the beginning of the numerical beach $(x=49.92 \mathrm{~m}$ ) was calculated for each linear damping coefficient. The ratio value for each simulation is presented in Table 3.

Table 3. Wave height ratio for each value of linear damping coefficient analyzed.

\begin{tabular}{cc}
\hline Values of $\boldsymbol{C}_{\mathbf{1}}$ & Wave Height Ratio (\%) \\
\hline 5 & 2.15 \\
15 & 0.13 \\
25 & 0.07 \\
50 & 0.06 \\
100 & 0.06 \\
\hline
\end{tabular}

One can observe in Table 3 that the smallest ratio values were the ones obtained with $C_{1}$ values of 50 and 100 . However, the difference between them and the ratio value for $C_{1}$ equals 25 was negligible. As this result is rather similar to that obtained by Lisboa et al. [34], a linear damping coefficient of 25 was adopted. 


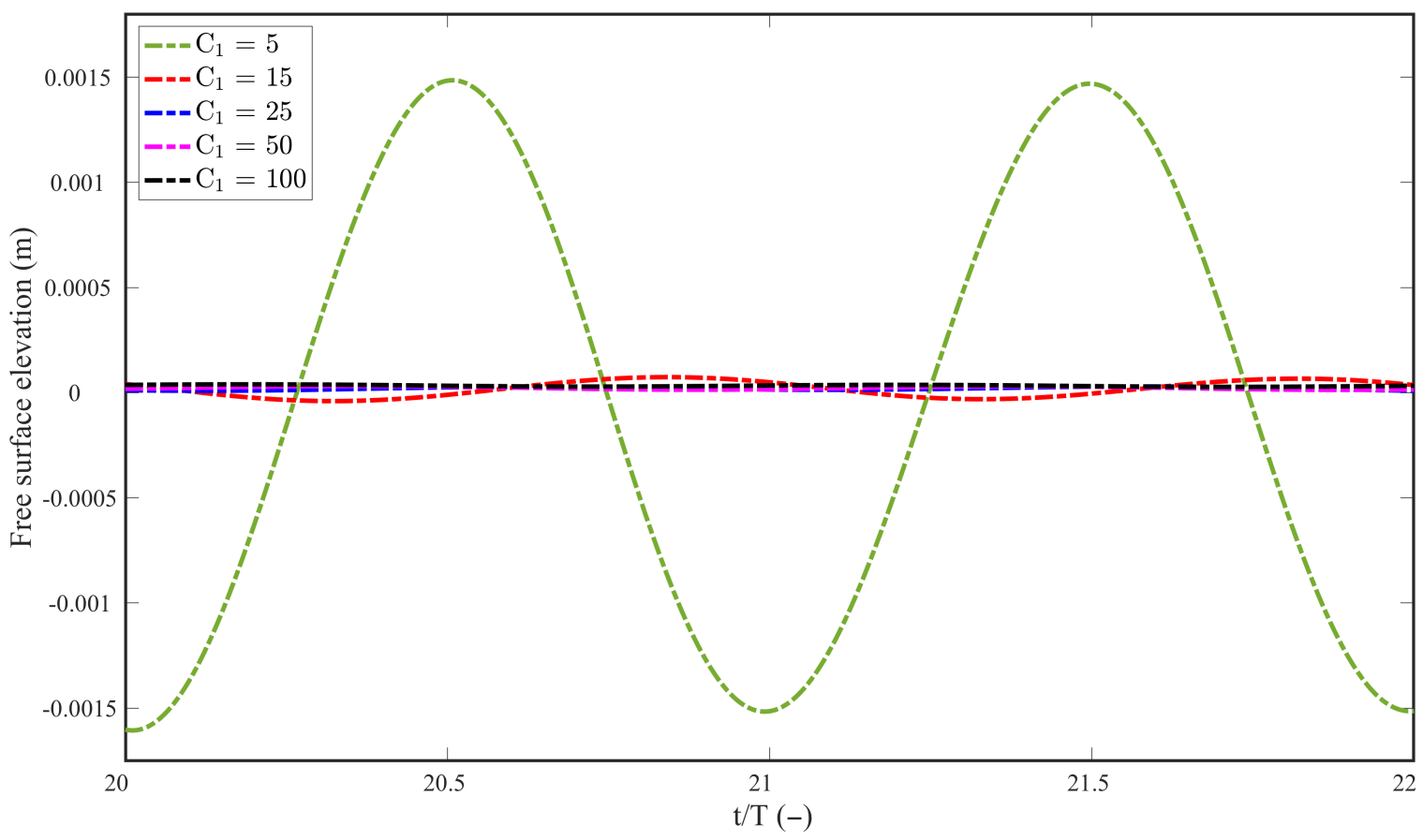

Figure 11. Comparison of free surface elevation at the end of the channel, according to the values adopted for numerical beach coefficient $C_{1}$.

\subsubsection{Mesh Study}

Next, mesh spatial discretization was analyzed. For that, four simulations were performed, with eight line segments at the region of wave generation and a $C_{1}$ coefficient value of 25 at the numerical beach. In each simulation, a different mesh was employed, using the dimensions presented in Table 1.

The analysis was performed using Equation (11) and compared both numerical and analytical free surface elevation at position $x=10.00 \mathrm{~m}$. It should be mentioned that, at the beginning of every simulation, the wave channel is at rest and, due to the flow inertia, the first waves generated are more dampened, as it can be seen in Figure 10, leading to considerable deviations in the comparison with the analytical results. Therefore, this interval of time in which wave generation is not stable was disregarded. The comparison between the free surface elevation of each mesh tested and the analytical solution is presented in Figure 12, and the corresponding NRMSE values are presented in Table 4.

Table 4. NRMSE values for each mesh discretization analyzed.

\begin{tabular}{cc}
\hline Mesh Number & NRMSE (\%) \\
\hline 1 & 7.95 \\
2 & 4.27 \\
3 & 5.04 \\
4 & 1.15 \\
\hline
\end{tabular}

As expected, mesh number 1 , which contained a coarser grid, showed the greatest discrepancy, with a NRMSE value of $7.95 \%$. On the other hand, mesh number 4 , which possessed the finest grid, presented the smallest NRMSE value (1.15\%), and, therefore, it was adopted for the following simulations. 


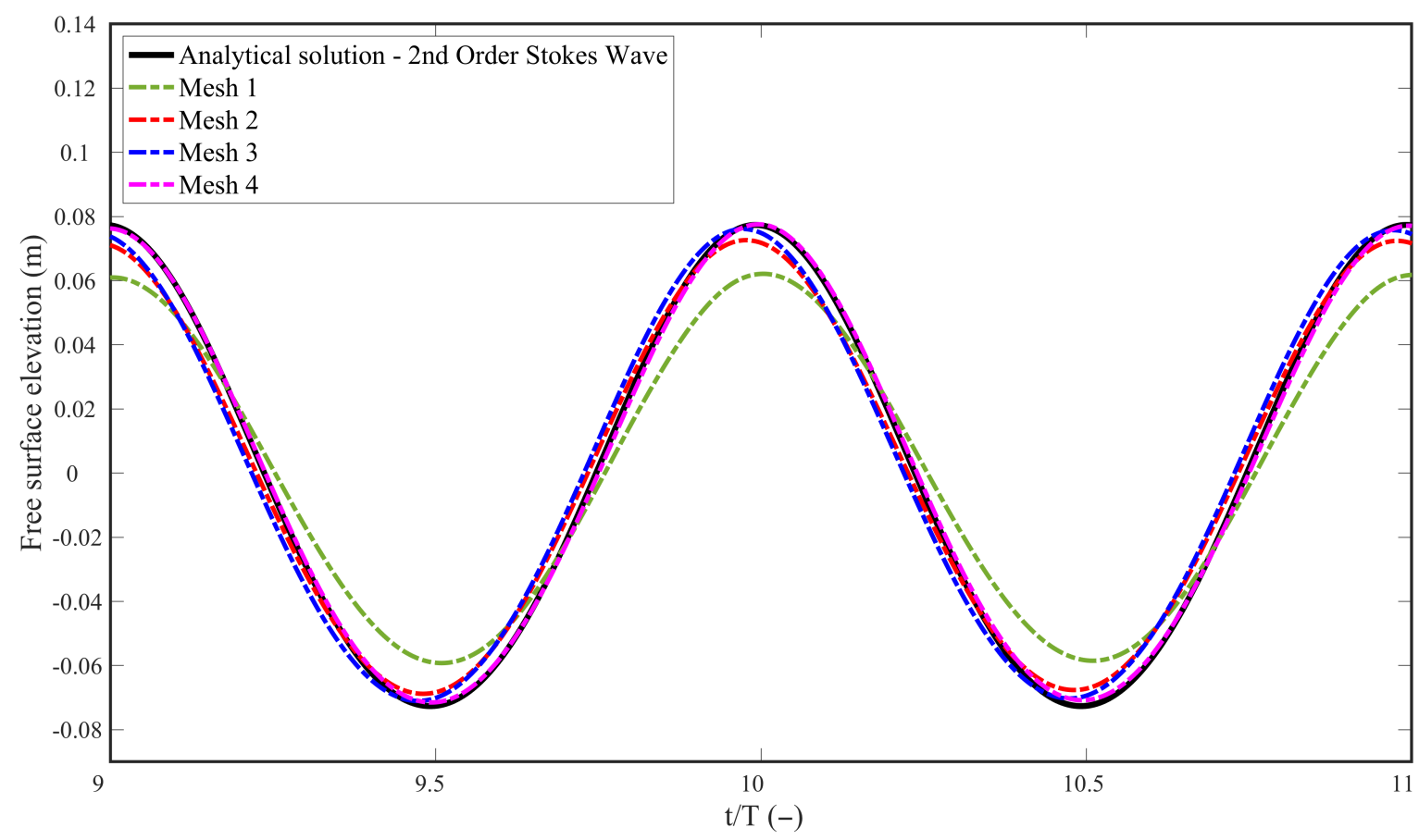

Figure 12. Comparison of mesh discretizations tested in this study.

\subsubsection{Time Step Analysis}

Since this is a transient problem, the time step influence was evaluated. For this analysis, mesh number 4 was employed, with eight line segments at the region of wave generation, and a $C_{1}$ coefficient value of 25 at the numerical beach. Five simulations were performed, varying the time step, using the values pointed in Section 2.2. The comparison between the numerical solution obtained with each time step tested and the analytical solution is presented in Figure 13, and the corresponding NRMSE values are presented in Table 5.

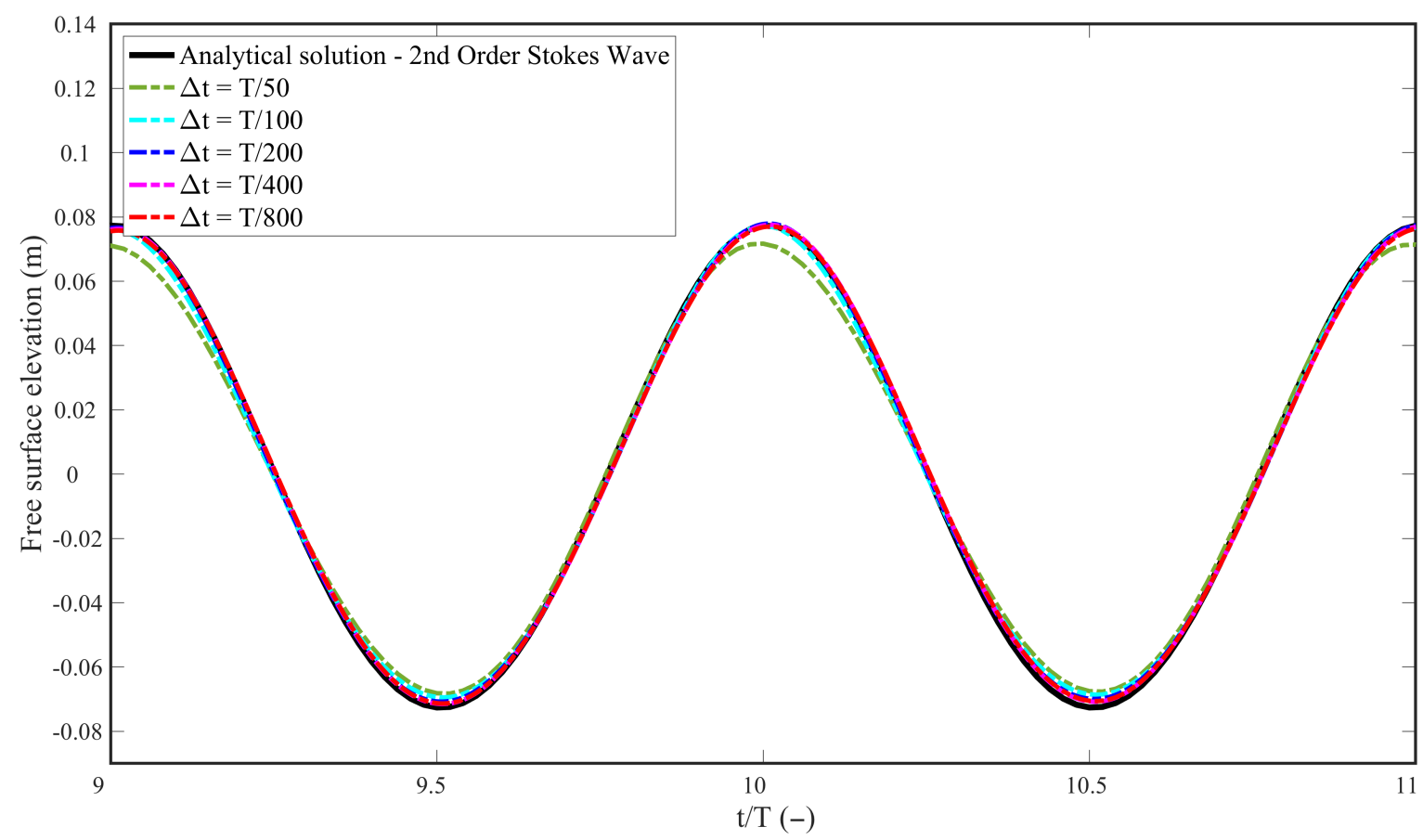

Figure 13. Comparison of time step values tested in this study. 
Table 5. NRMSE value for each time step analyzed.

\begin{tabular}{cc}
\hline Time step & NRMSE (\%) \\
\hline$T / 50$ & 3.45 \\
$T / 100$ & 2.15 \\
$T / 200$ & 1.46 \\
$T / 400$ & 1.15 \\
$T / 800$ & 1.16 \\
\hline
\end{tabular}

As it can be seen in Figure 13 and Table 5, free surface elevation was more dissonant when using $\Delta t$ equals $T / 50$. It should be highlighted that the NRMSE value found using this temporal discretization can be considered fairly small. However, the smallest NRMSE was obtained with a time step equal to $T / 400$. It is also worth mentioning that an approximate value was encountered by Gomes et al. [31], who reached good results with a time step of $T / 500$. Thus, the time step value of $T / 400$ was adopted for the simulation of the validation procedure.

\subsection{Validation}

The verification tests performed included analysis of the discretization at the region of velocity imposition, linear damping coefficient $C_{1}$ at the numerical beach, mesh spatial discretization, and temporal discretization, thus ensuring a proper wave generation and propagation. Optimal results were obtained with eight line segments at the region of wave generation, $C_{1}$ equal to 25 , mesh elements throughout the channel with dimensions of $L / 40$, mesh elements inside free surface refinement zone with dimensions of $H / 25$, and a time step value of $T / 400$.

Then, the OWC device was inserted into the numerical wave channel and three simulations were performed, using either laminar flow or turbulent flow, with turbulence models $k-\epsilon$ and $k-\omega \mathrm{SST}$. With the results obtained from these simulations, the free surface elevation obtained by the numerical gauges located outside and inside the hydropneumatic chamber was compared with wave gauges WG1, WG2, WG3, and WG4 (see Figure 9 for more details). The pressure obtained by the numerical probe located inside the hydropneumatic chamber was also compared with the pressure sensor used in the experiment.

The free surface elevation for wave gauges WG1, WG2, WG3, and WG4 can be seen in Figures 14-17, instantaneous free surface flow near the OWC device is shown in Figure 18, and the air pressure inside the hydropneumatic chamber is presented in Figure 19. All results are presented for five wave cycles, the NRMSE for each simulation was calculated, in comparison to the experimental results, and it is shown in Table 6.

Table 6. NRMSE values for numerical wave gauges and pressure sensor.

\begin{tabular}{cccccc}
\hline \multirow{2}{*}{ Flow Regime } & \multicolumn{5}{c}{ NRMSE (\%) } \\
\cline { 2 - 6 } & WG1 & WG2 & WG3 & WG4 & PS \\
\hline Laminar flow & 3.37 & 5.07 & 9.35 & 5.27 & 4.22 \\
Turbulent $-k-\epsilon$ & 3.27 & 5.03 & 8.23 & 4.93 & 4.40 \\
Turbulent $-k-\omega$ SST & 3.32 & 5.16 & 9.03 & 5.11 & 4.63 \\
\hline
\end{tabular}

As indicated in Figure 9, wave gauges WG1 and WG2 were located previously to the OWC device, which has less effect of nonlinearity. This aspect can be observed in both numerical and experimental results of Figures 14 and 15, where it is possible to observe that the free surface elevation follows a more regular pattern.

As Zabihi et al. [40] affirmed, nonlinear interactions are more noticeable inside the hydropneumatic chamber; this explains greater NRMSE values for wave gauges WG3 and WG4, which were located inside the chamber. As it can be observed in Figure 16, there 
were some disparities between wave crests of numerical and experimental results for WG3; however, that is less evident in WG4 (Figure 17).

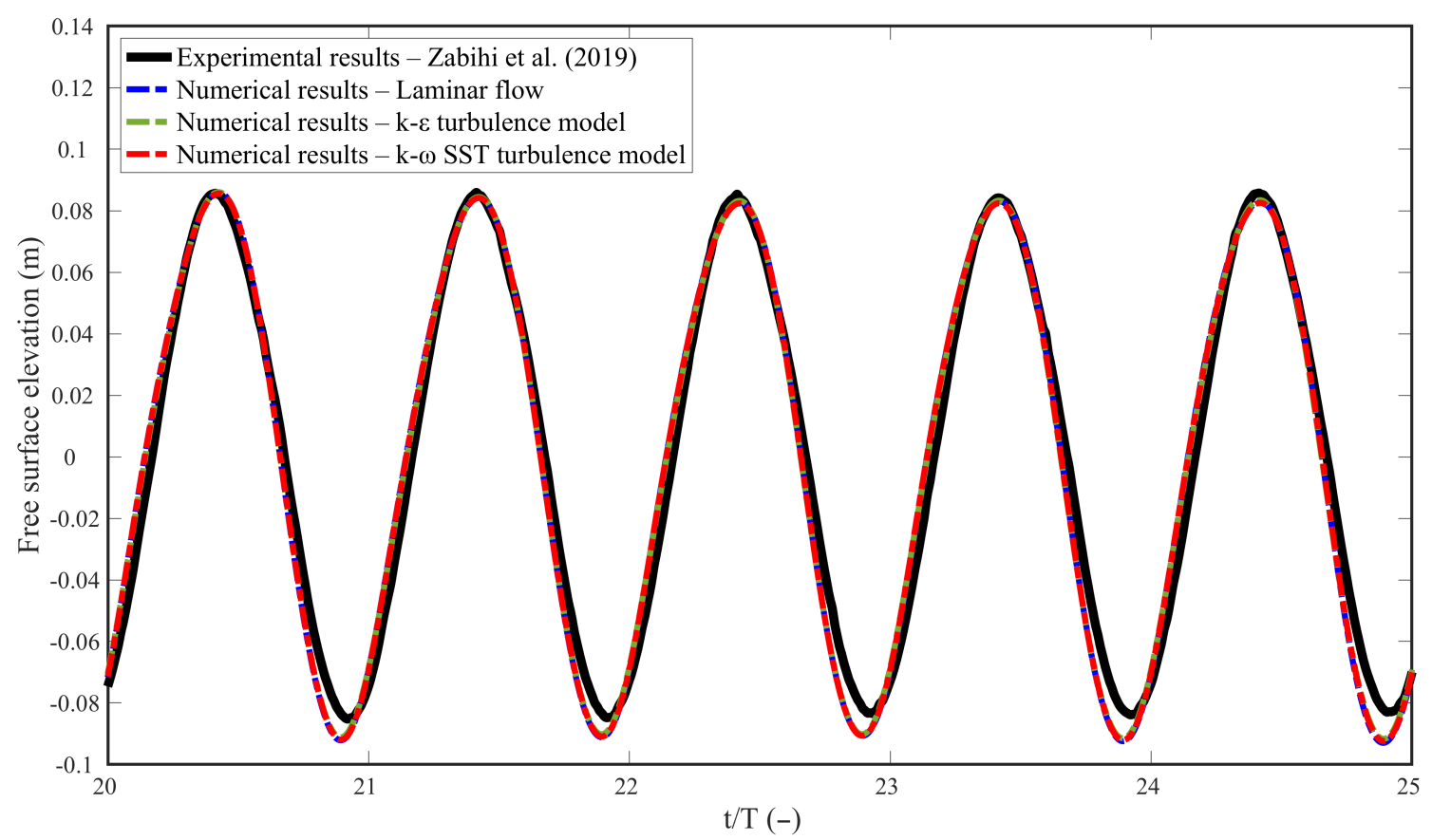

Figure 14. Free surface elevation at wave gauge WG1, located outside the hydropneumatic chamber. Experimental versus numerical results.

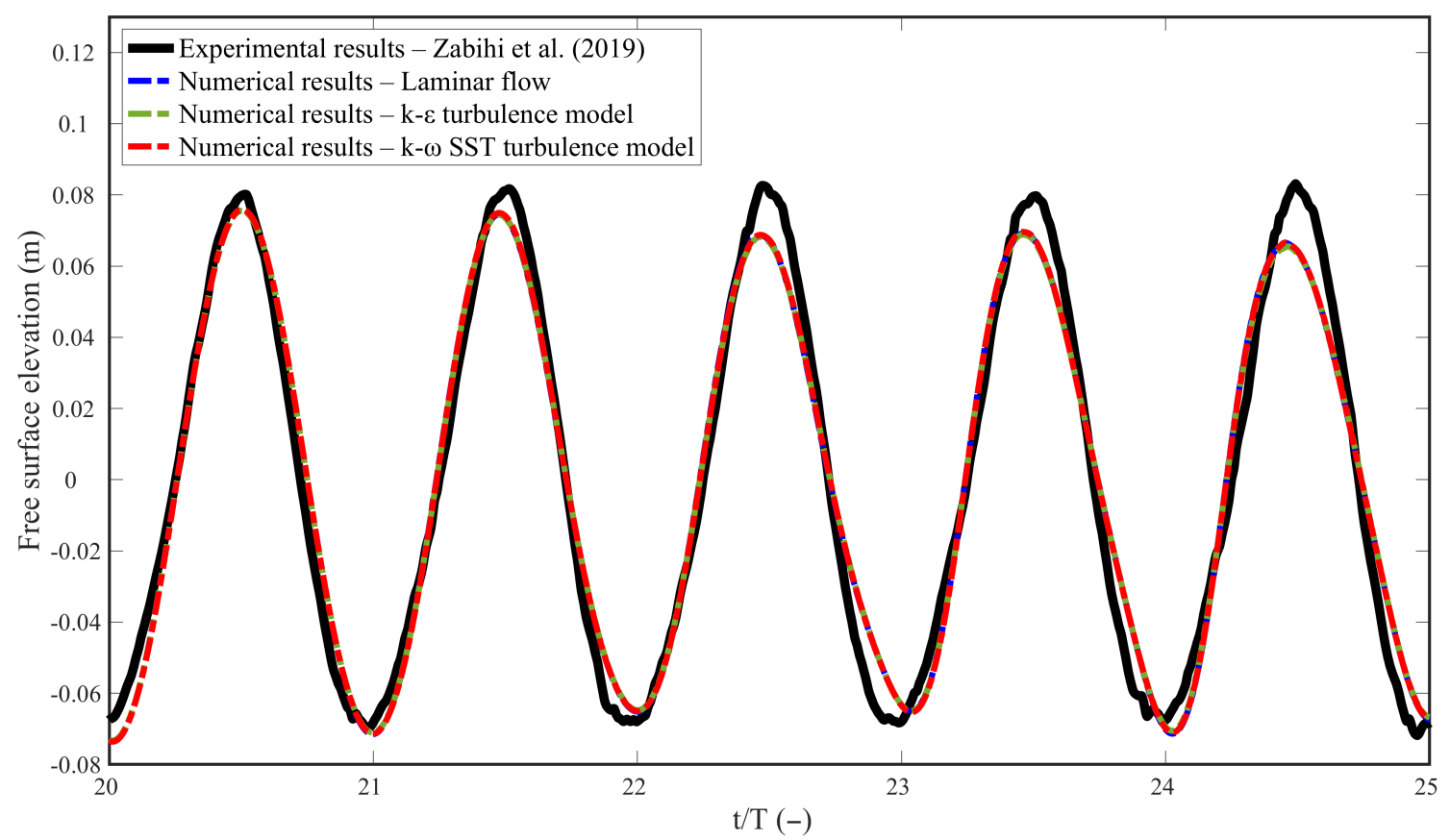

Figure 15. Free surface elevation at wave gauge WG2, located outside the hydropneumatic chamber. Experimental versus numerical results. 


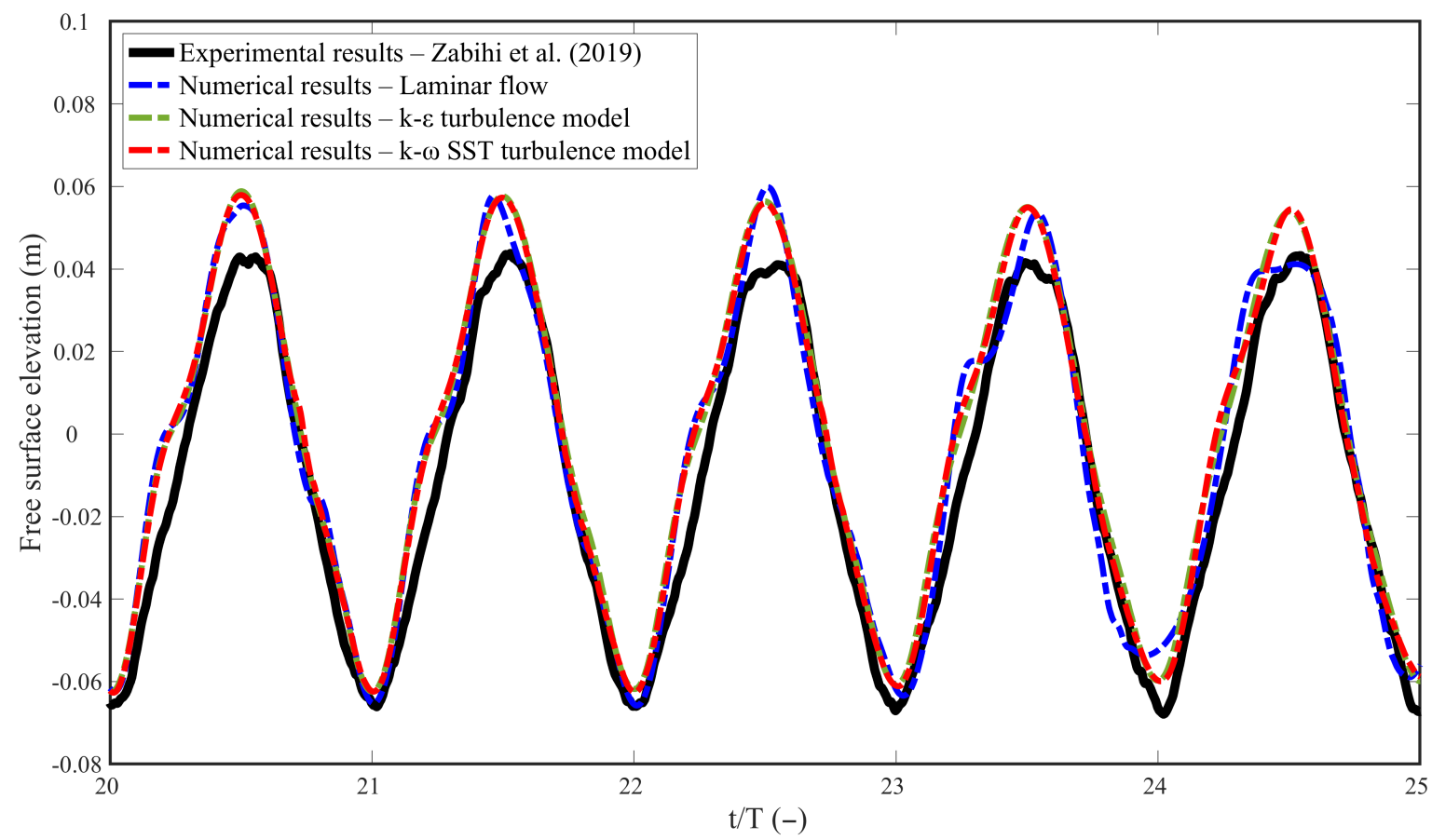

Figure 16. Free surface elevation at wave gauge WG3, located inside the hydropneumatic chamber. Experimental versus numerical results.

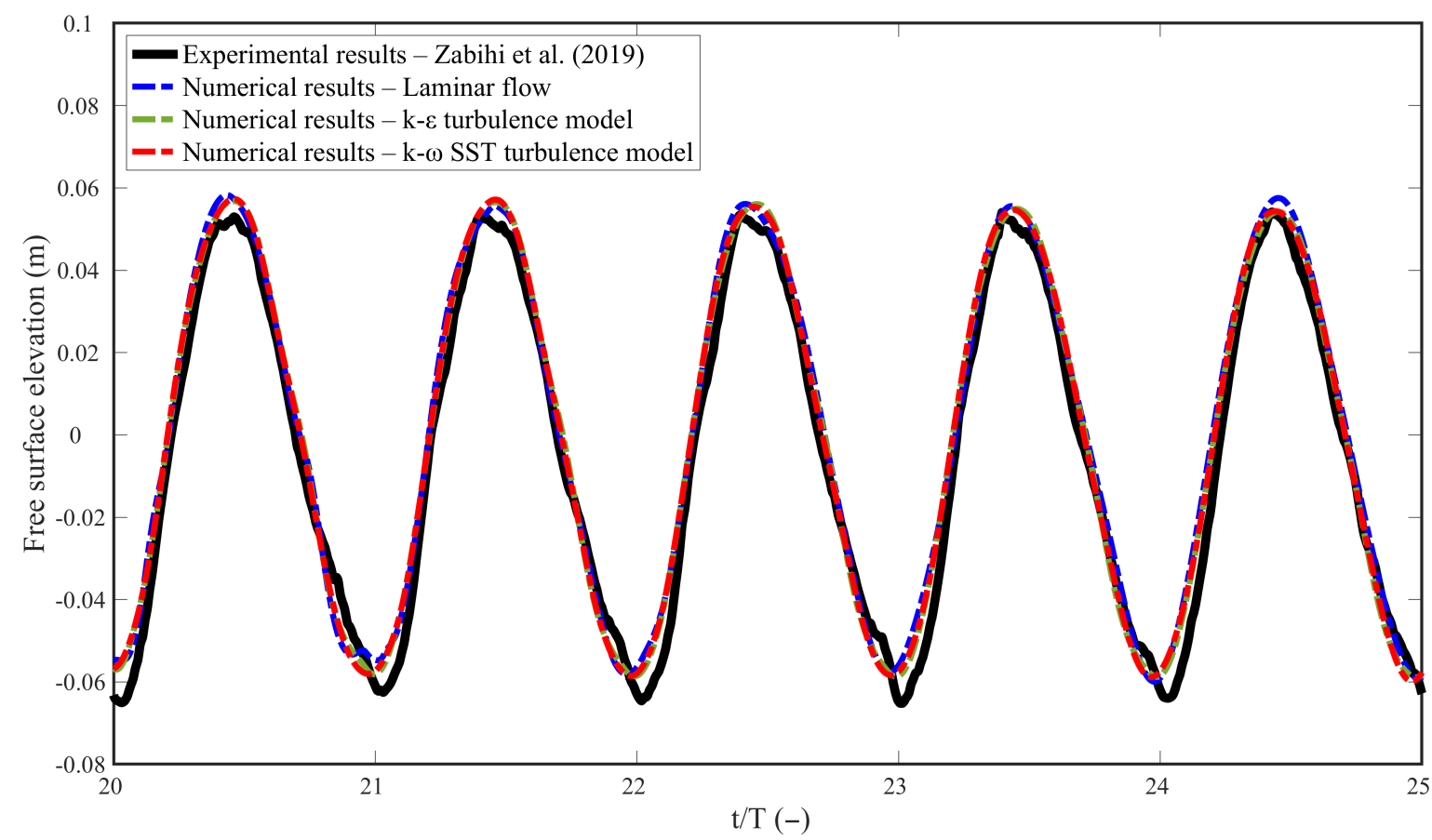

Figure 17. Free surface elevation at wave gauge WG4, located inside the hydropneumatic chamber. Experimental versus numerical results.

In addition, water free surface flow for nine instants along a wave period is presented in Figure 18. One can observe how wave crests and troughs are more accentuated previously to the hydropneumatic chamber than afterwards, due to the wave damping when interacting with the walls of the device. 

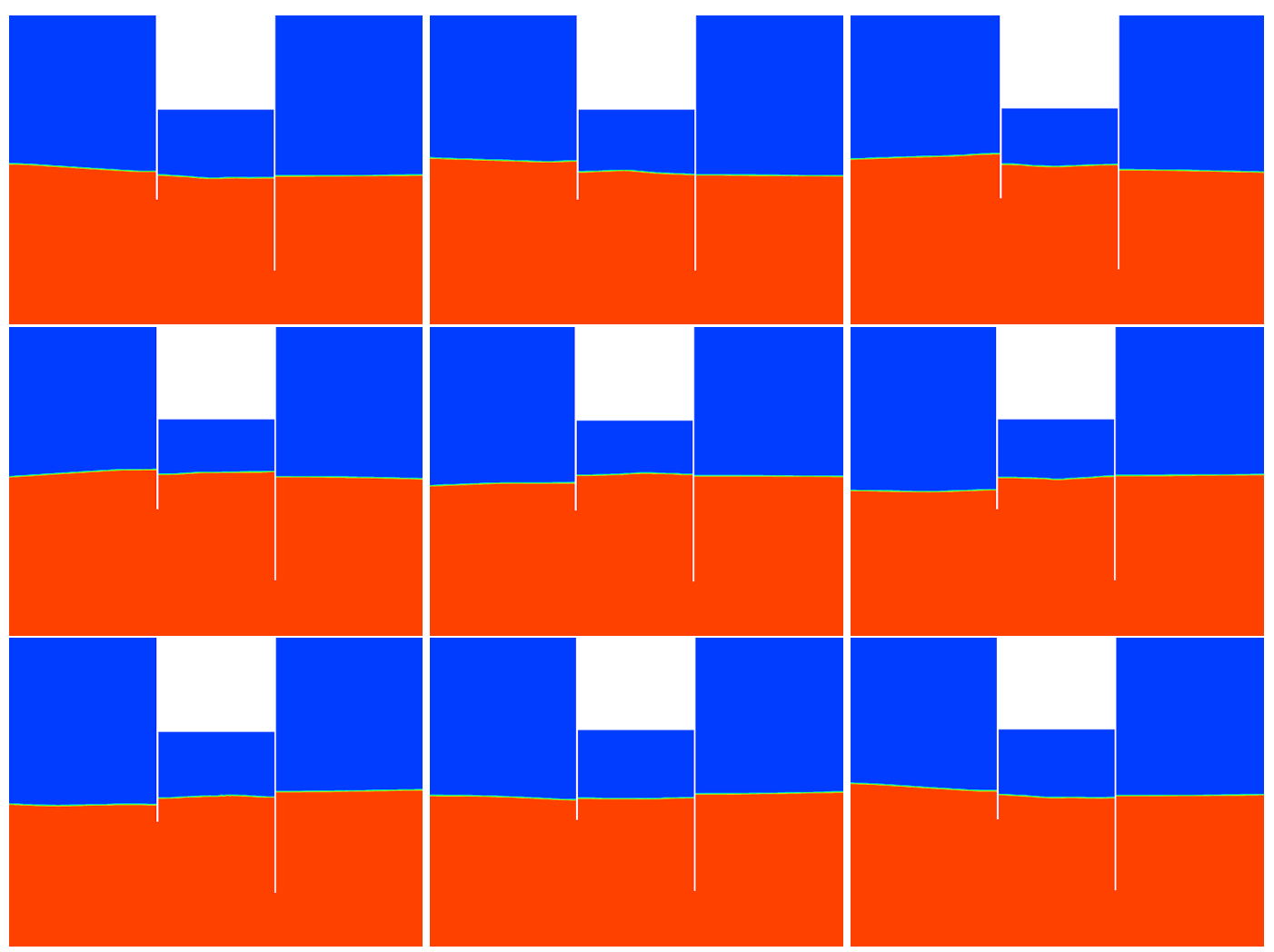

Figure 18. Instantaneous free surface flow near the OWC device along one wave period.

The air pressure inside the hydropneumatic chamber was also analyzed, for it is significant when reproducing the hydrodynamics of the OWC device, and it can be seen in Figure 19. It should be highlighted that the numerical results presented excellent accordance with the experimental results, being able to capture the general behavior present in the device.

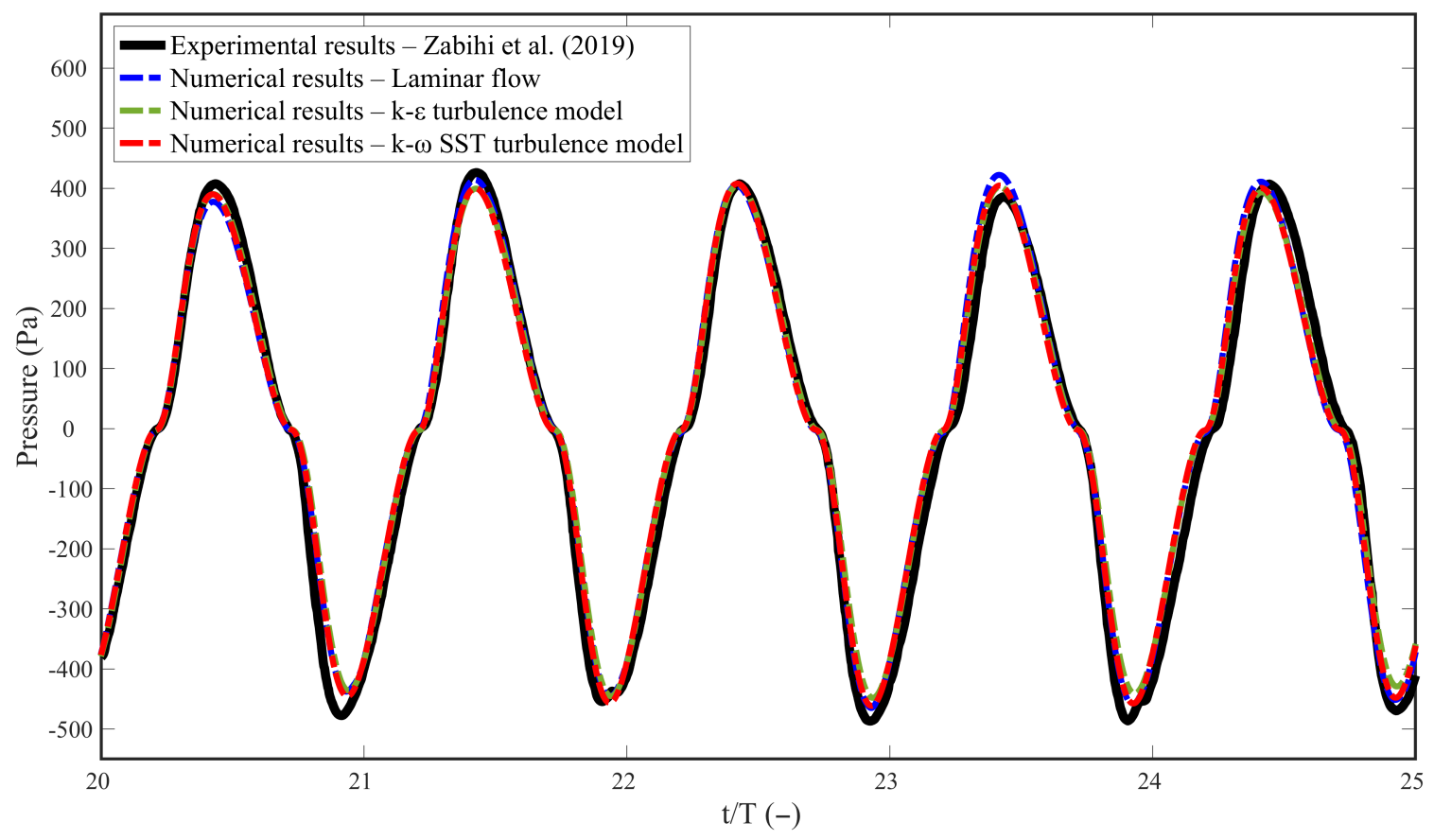

Figure 19. Air pressure inside the hydropneumatic chamber, experimental versus numerical results. 
As one can note, overall, numerical results presented a good agreement with the results from the experiments, although nonlinear interactions were more present in WG3. From the NRMSE values, it is possible to notice that the $k-\epsilon$ turbulence model provided a behavior more similar to those found in the experiments.

\section{Conclusions}

The oscillating water column (OWC) converter device is one of the most extensively studied in the literature. It has been studied through various approaches: analytical, experimental, and numerical. Due to its capacity of simulating devices and their physical phenomena, while taking into account wave characteristics with accuracy, numerical procedures have been increasingly applied.

In this paper, a two-dimensional numerical analysis of a wave channel and a laboratory scale OWC device was performed. This analysis employed a methodology which uses transient velocity data as a means to impose velocity boundary conditions for the generation of numerical waves. The simulations were performed using regular waves with the same wave parameters as those used in a laboratory experiment. These waves were imposed as prescribed velocity boundary conditions and compared with the analytical solution. Then, the OWC device was inserted in the computational domain, aiming to validate the methodology employed.

Several tests were performed to ensure proper wave generation, including the discretization at the region of velocity imposition, the linear damping coefficient $C_{1}$ at the numerical beach, mesh spatial discretization, and temporal discretization. Optimal results were obtained with eight line segments at the region of wave generation, $C_{1}$ equal to 25 , mesh elements throughout the channel with dimensions of $L / 40$, mesh elements inside free surface refinement zone with dimensions of $H / 25$, and a time step value of $T / 400$.

For the validation case, although there were some disparities, in general, the numerical results showed a good agreement with the laboratory experiment results. It should be highlighted that $k-\epsilon$ turbulence model could best represent the flow inside the wave channel.

The contribution of this paper is the validation of a recently proposed methodology for the imposition of transient velocity data as the boundary conditions in the generation of numerical waves. Since most studies use regular waves, there is a lack of analyses that use ocean waves realistic data. In this context, this methodology is innovative as it allows the use of realistic sea state data in numerical simulations regarding WECs.

Author Contributions: Conceptualization-R.P.M., B.N.M., M.N.G. and L.A.I.; methodologyR.P.M., M.N.G. and L.A.I.; software-R.P.M., B.N.M. and M.N.G.; validation-R.P.M., B.N.M., M.N.G. and L.A.I.; formal analysis-C.F., L.A.O.R. and E.D.d.S.; investigation-R.P.M., B.N.M., M.N.G. and L.A.I.; resources-C.F., L.A.O.R., E.D.d.S. and L.A.I.; data curation-R.P.M., B.N.M., M.N.G.; writing (original draft preparation)—R.P.M. and B.N.M.; writing (review and editing)—C.F., B.N.M., L.A.O.R., E.D.d.S., M.N.G. and L.A.I.; visualization-C.F., L.A.O.R. and E.D.d.S.; supervision-M.N.G. and L.A.I.; project administration-B.N.M., M.N.G. and L.A.I.; funding acquisition-L.A.O.R., E.D.d.S. and L.A.I. All authors have read and agreed to the published version of the manuscript.

Funding: This research was funded by Brazilian National Council for Scientific and Technological Development-CNPq (processes: 440020/2019-0; 307791/2019-0; 306024/2017-9; and 306012/20170 ); and the Research Support Foundation of the State of Rio Grande do Sul-FAPERGS (process: 17/2551-0001111-2).

Institutional Review Board Statement: Not applicable.

Informed Consent Statement: Not applicable.

Data Availability Statement: The data presented in this study are available on request from the corresponding author. The data are not publicly available due to privacy reasons.

Acknowledgments: R.P. Maciel thanks CNPq for the Master Dissertation Scholarship (Chamada CNPq/EQUINOR Energia Ltda. 2018, process 440020/2019-0). L.A.O. Rocha, E.D. dos Santos, and L.A. Isoldi thank CNPq for the research grant (processes: 307791/2019-0; 306024/2017-9; and 
306012/2017-0). B.N. Machado thanks Brazilian Coordination for the Improvement of Higher Education Personnel-CAPES, for the Post-Doc Scholarship. L.A. Isoldi thanks FAPERGS (Edital 02/2017-PqG, process: 17/2551-0001111-2). All authors thank Milad Zabihi for kindly sharing experimental data, which were essential for the writing of the present paper.

Conflicts of Interest: The authors declare no conflict of interest. The funders had no role in the design of the study; in the collection, analyses, or interpretation of data; in the writing of the manuscript, or in the decision to publish the results.

\section{References}

1. World Water Assessment Programme. The United Nations World Water Development Report 3: Water in a Changing World; Technical Report; UNESCO: Paris, France, 2009. [CrossRef]

2. Hil Baky, M.A.; Rahman, M.M.; Islam, A.K. Development of renewable energy sector in Bangladesh: Current status and future potentials. Renew. Sustain. Energy Rev. 2017, 73, 1184-1197. [CrossRef]

3. International Energy Agency. World Energy Balances 2017; Technical Report; International Energy Agency: Paris, France, 2017.

4. $\quad$ Empresa de Pesquisa Energética. Balanço Energético Nacional 2018: Ano Base 2017; Technical Report; Ministério de Minas e Energia: Rio de Janeiro, Brazil, 2018. (In Portuguese)

5. Ressurreição, A.; Gibbons, J.; Dentinho, T.P.; Kaiser, M.; Santos, R.S.; Edwards-Jones, G. Economic valuation of species loss in the open sea. Ecol. Econ. 2011, 70, 729-739. [CrossRef]

6. Melikoglu, M. Current status and future of ocean energy sources: A global review. Ocean Eng. 2018, 148, 563-573. [CrossRef]

7. Espindola, R.L.; Araújo, A.M. Wave energy resource of Brazil: An analysis from 35 years of ERA-Interim reanalysis data. PLoS ONE 2017, 12, e0183501. [CrossRef] [PubMed]

8. Falcão, A.F.O.; Henriques, J.C.C. Oscillating-water-column wave energy converters and air turbines: A review. Renew. Energy 2016, 85, 1391-1424. [CrossRef]

9. Machado, B.N.; Kisner, E.V.; Paiva, M.D.S.; Gomes, M.D.N.; Rocha, L.A.O.; Marques, W.C.; dos Santos, E.D.; Isoldi, L.A. Numerical Generation of Regular Waves Using Discrete Analytical Data As Boundary Condition of Prescribed Velocity. In Proceedings of the XXXVIII Iberian Latin American Congress on Computational Methods in Engineering, Florianopolis, Brazil, 5-8 November 2017. [CrossRef]

10. Hudspeth, R.T.; Guenther, R.B. Wavemaker Theories. In Handbook of Coastal and Ocean Engineering; Kim, Y.C., Ed.; World Scientific: Singapore, 2009; pp. 25-56. [CrossRef]

11. Dean, R.G.; Dalrymple, R.A. Water Wave Mechanics for Engineers and Scientists; World Scientific Publishing Company: Singapore, 1991 ; Volume 2, p. 368.

12. Liu, Z.; Hyun, B.S.; Jin, J. Numerical Prediction for Overtopping Performance of OWEC. In Proceedings of the Oceans 2008-MTS/IEEE Kobe Techno-Ocean, Kobe, Japan, 8-11 April 2008; p. 6. [CrossRef]

13. Gomes, M.N.; Isoldi, L.A.; Olinto, C.R.; Rocha, L.A.; Souza, J.A. Computational modeling of a regular wave tank. Therm. Eng. 2009, 8, 44-50. [CrossRef]

14. Liu, Z.; Hyun, B.S.; Hong, K. Numerical study of air chamber for oscillating water column wave energy convertor. China Ocean Eng. 2011, 25, 169-178. [CrossRef]

15. Du, Q.; Leung, D.Y. 2D Numerical Simulation of Ocean Waves. In Proceedings of the World Renewable Energy Congress 2011, Linkoping, Sweden, 8-13 May 2011; Volume 57, pp. 2183-2189. [CrossRef]

16. Kusumawinahyu, W.M.; Karjanto, N.; Klopman, G. Linear theory for single and double flap wavemakers. J. Indones. Math. Soc. 2006, 12, 41-57.

17. Lal, A.; Elangovan, M. CFD Simulation and Validation of Flap Type Wave-Maker. World Acad. Sci. Eng. Technol. 2008, 48, 76-82.

18. Elangovan, M. Simulation of irregular waves by CFD. Int. J. Mech. Mechatron. Eng. 2011, 5, 1379-1383. [CrossRef]

19. Krvavica, N.; Ružić, I.; Ožanić, N. New approach to flap-type wavemaker equation with wave breaking limit. Coast. Eng. J. 2018, 60, 10. [CrossRef]

20. Wu, Y.C. Plunger-type wavemaker theory. J. Hydraul. Res. 1988, 26, 483-491. [CrossRef]

21. Wu, Y.C. Waves generated by a plunger-type wavemaker. J. Hydraul. Res. 1991, 29, 851-860. [CrossRef]

22. Lowell, S.; Irani, R.A. Sensitivity analysis of plunger-type wavemakers with water current. In Proceedings of the IEEE Global OCEANS 2020: Singapore-U.S. Gulf Coast, Biloxi, MS, USA, 5-30 October 2020; p. 9. [CrossRef]

23. He, M.; Khayyer, A.; Gao, X.; Xu, W.; Liu, B. Theoretical method for generating solitary waves using plunger-type wavemakers and its Smoothed Particle Hydrodynamics validation. Appl. Ocean. Res. 2021, 106, 30. [CrossRef]

24. Doustdar, M.M.; Kazemi, H. Effects of fixed and dynamic mesh methods on simulation of stepped planing craft. J. Ocean. Eng. Sci. 2019, 4, 33-48. [CrossRef]

25. Oliveira, L.O.D.; Teixeira, P.R.; Dos Santos, E.D.; Isoldi, L.A. Constructal design applied to the geometric optimization of the hydropneumatic chamber dimensions of an Oscillating Water Column wave energy device. In Proceedings of the 11th Youth Symposium on Experimental Solid Mechanics, Brasov, Romania, 30 May-2 June 2012; pp. 173-178.

26. Gomes, M.N.; Nascimento, C.D.; Bonafini, B.L.; Santos, E.D.; Isoldi, L.A.; Rocha, L.A.O. Two-Dimensional Geometric Optimization of an Oscillating Water Column Converter in Laboratory Scale. Therm. Eng. 2012, 11, 30. [CrossRef] 
27. Gomes, M.d.N.; Seibt, F.M.; Rocha, L.A.O.; dos Santos, E.D.; Isoldi, L.A. Numerical analysis of an oscillating water column converter considering a physical constraint in the chimney outlet. Mar. Syst. Ocean Technol. 2014, 9, 85-93. [CrossRef]

28. Lorenzini, G.; Lara, M.F.E.; Rocha, L.A.O.; Gomes, M.D.N.; Dos Santos, E.D.; Isoldi, L.A. Constructal design applied to the study of the geometry and submergence of an Oscillating Water Column. Int. J. Heat Technol. 2015, 33, 31-38. [CrossRef]

29. Lima, Y.T.B.; Rocha, L.A.O.; Gomes, M.d.N.; Isoldi, L.A.; dos Santos, E.D. Numerical Evaluation of Hydropneumatic Power for Two Oscillating Water Column (OWC) Devices Coupled Using Constructal Design. In Proceedings of the XXXVIII Iberian Latin American Congress on Computational Methods in Engineering, Florianopolis, Brazil, 5-8 November 2017; [CrossRef]

30. Lisboa, R.C.; Teixeira, P.R.; Torres, F.R.; Didier, E. Numerical evaluation of the power output of an oscillating water column wave energy converter installed in the southern Brazilian coast. Energy 2018, 162, 1115-1124. [CrossRef]

31. Gomes, M.N.; Lorenzini, G.; Rocha, L.A.; dos Santos, E.D.; Isoldi, L.A. Constructal Design Applied to the Geometric Evaluation of an Oscillating Water Column Wave Energy Converter Considering Different Real Scale Wave Periods. J. Eng. Thermophys. 2018, 27, 173-190. [CrossRef]

32. Hübner, R.G.; Oleinik, P.H.; Marques, W.C.; Gomes, M.N.; dos Santos, E.D.; Machado, B.N.; Isoldi, L.A. Numerical Study Comparing the Incidence Influence Between Realistic Wave and Regular Wave Over an Overtopping Device. Therm. Eng. 2019, 18, 46. [CrossRef]

33. Hardy, P.; Cazzolato, B.S.; Ding, B.; Prime, Z. A maximum capture width tracking controller for ocean wave energy converters in irregular waves. Ocean Eng. 2016, 121, 516-529. [CrossRef]

34. Lisboa, R.C.; Teixeira, P.R.F.; Didier, E. Regular and Irregular Wave Propagation Analysis in a Flume with Numerical Beach Using a Navier-Stokes Based Model. Defect Diffus. Forum 2017, 372, 81-90. [CrossRef]

35. Têtu, A. Power Take-Off Systems for WECs. In Handbook of Ocean Wave Energy; Pecher, A., Kofoed, J.P., Eds.; Springer: Berlin/Heidelberg, Germany, 2017; Chapter 8, pp. 203-220. [CrossRef]

36. Gao, H.; Yu, Y. The dynamics and power absorption of cone-cylinder wave energy converters with three degree of freedom in irregular waves. Energy 2018, 143, 833-845. [CrossRef]

37. Gomes, M.d.N.; De Deus, M.J.; Dos Santos, E.D.; Isoldi, L.A.; Rocha, L.A.O. Analysis of the geometric constraints employed in constructal design for oscillating water column devices submitted to the wave spectrum through a numerical approach. Defect Diffus. Forum 2019, 390, 193-210. [CrossRef]

38. Tay, Z.Y. Energy extraction from an articulated plate anti-motion device of a very large floating structure under irregular waves. Renew. Energy 2019, 130, 206-222. [CrossRef]

39. Tavares, G.P.; Maciel, R.P.; dos Santos, E.D.; Gomes, M.d.N.; Rocha, L.A.O.; Machado, B.N.; Oleinik, P.H.; Isoldi, L.A. A Comparative Numerical Analysis of the Available Power Between Regular and Irregular Waves: Case Study of an Oscillating Water Column Converter in Rio Grande Coast, Brazil. In Procceedings of the 18th Brazilian Congress of Thermal Sciences and Engineering, online, 16-20 November 2020; p. 11. [CrossRef]

40. Zabihi, M.; Mazaheri, S.; Namin, M.M. Numerical Validation of Experimental Tests Conducted on a Fixed Offshore Oscillating Water Column. Int. J. Coast. Offshore Eng. 2019, 2, 1-8. [CrossRef]

41. ANSYS Inc. Ansys Fluent Theory Guide; ANSYS, Inc.: Cannonsburg, PA, USA, 2013.

42. Schlichting, H.; Gersten, K. Boundary-Layer Theory, 8th ed.; Springer: Berlin, Germany, 2000; p. 802. [CrossRef]

43. Meier, G.E.A.; Sreenivasan, K.R. (Eds.) IUTAM Symposium on One Hundred Years of Boundary Layer Research. In Proceedings of the International Union of Theoretical and Applied Mechanics Symposium; Springer: Göttingen, Germany, $2004 ;$ p. 507.

44. Gonçalves, R.A.A.C.; Teixeira, P.R.F.; Didier, E.; Torres, F.R. Numerical analysis of the influence of air compressibility effects on an oscillating water column wave energy converter chamber. Renew. Energy 2020, 153, 1183-1193. [CrossRef]

45. Hirt, C.W.; Nichols, B.D. Volume of fluid (VOF) method for the dynamics of free boundaries. J. Comput. Phys. 1981, 39, 201-225. [CrossRef]

46. Gopala, V.R.; van Wachem, B.G. Volume of fluid methods for immiscible-fluid and free-surface flows. Chem. Eng. J. 2008, 141, 204221. [CrossRef]

47. Srinivasan, V.; Salazar, A.J.; Saito, K. Modeling the disintegration of modulated liquid jets using volume-of-fluid (VOF) methodology. Appl. Math. Model. 2011, 35, 3710-3730. [CrossRef]

48. Neill, S.P.; Hashemi, M.R. Chapter 8-Ocean Modelling for Resource Characterization. In Fundamentals of Ocean Renewable Energy; Neill, S.P., Hashemi, M.R., Eds.; E-Business Solutions; Academic Press: Cambridge, MA, USA, 2018; pp. 193-235. [CrossRef]

49. Misra, S.; He, J. Chapter 3-Shallow neural networks and classification methods for approximating the subsurface in situ fluid-filled pore size distribution. In Machine Learning for Subsurface Characterization; Misra, S., Li, H., He, J., Eds.; Gulf Professional Publishing: Houston, TX, USA,2020; pp. 65-101. [CrossRef]

50. Geuzaine, C.; Remacle, J.F. Gmsh: A 3-D finite element mesh generator with built-in pre- and post-processing facilities. Int. J. Numer. Methods Eng. 2009, 79, 1309-1331. [CrossRef]

51. Perić, R.; Abdel-Maksoud, M. Reliable damping of free-surface waves in numerical simulations. Ship Technol. Res. 2016, 63, 1-13. [CrossRef] 